\title{
Blacks and psychiatry: a framework for understanding access to psychiatric services
}

\author{
Parimala Moodley, Senior Lecturer in Community Mental Health, Institute of \\ Psychiatry, Denmark Hill, London SE5 8AF; and RACHEL E. PERKINS, Principal \\ Clinical Psychologist (Rehabilitation), Springfield University Hospital, Glenburnie \\ Road, London SW17 7DJ
}

In efforts to improve the acceptability of psychiatric services and their ease of access, the issue of how people get psychiatric help when they need it is one of growing concern. There is now increasing evidence that psychiatric services operate differently for black and white people in Britain, and much concern that services may differentially disadvantage blacks (Francis et al, 1989).

A number of studies indicate that Afro-Caribbeans are over-represented among compulsory admissions (e.g. Ineichen et al, 1984). In addition, there is evidence of a higher level of police involvement and a lower level of GP involvement in admissions of Caribbean patients (e.g. Harrison et al, 1988). However evidence of differential service use is incomplete. To date there has been little consideration of any overall framework for understanding differential uptake of services. As a result efforts to improve service provision are likely to be piecemeal and ignore the complex set of interactions between different parts of services and their users. A clear framework for understanding service operation is therefore essential.

Probably the best articulated model now available is the 'filter model' of Goldberg \& Huxley (1980) which describes the routes people take to psychiatric care. With its emphasis on the role of the GP, this model fails to encompass the evidence concerning routes taken to psychiatric care by black patients. It also fails to incorporate those people who present themselves directly to psychiatric services (emergency clinical, wards, etc.); those who come by way of general medical services (accident and emergency departments, liaison services, etc.); those who come through the legal system (courts, police, etc.); or those whose initial contact is with one of the increasing number of voluntary sector or social services. If the variety of ways in which people gain access to psychiatric services is to be understood and systematically investigated a more comprehensive model is required. Fig. 1 illustrates such a model.

In this model it is proposed that there are five major routes of access to psychiatric services. Medical services form one such gateway by way of either accident and emergency provision or the various liaison psychiatry services available. Such access may be particularly common among those who construe their problems as physical rather than psychiatric or those whose admission has been precipitated by a suicide attempt. These services are usually readily accessible and may be considered a more acceptable source of help given the stigma attached to mental illness. The quality of liaison between medical and psychiatric services is likely to determine the effectiveness of this route.

Although not well documented, it is becoming increasingly clear that some people present themselves directly to psychiatric services, either by themselves or at the instigation of their relatives or friends. The use of this route may be increased by the availability of 'walk-in' psychiatric emergency services. The location of such services, together with their acceptability and the way in which they are perceived by the local community, may also be important. With the development of community mental health centres and demise of remote psychiatric hospitals, use of this route is likely to increase.

The GP and primary care facilities continue to provide an important point of access to psychiatric services as described by Goldberg \& Huxley (1980).

As the number of statutory and voluntary community support agencies increases, they are likely to have a more important role both in the provision of care and in mediating access to psychiatric services, in theory, such agencies should be more responsive to local needs and therefore have the potential for providing a more acceptable form of access to help. Clearly, if services are to be delivered effectively the links between such agencies and psychiatric services are of crucial importance. Similarly, the training of psychiatric workers in liaison work with such agencies, and the training of social services/voluntary sector workers in detection of psychiatric problems and how to access resources is vital.

Within inner city areas access to services by way of the police and legal system is an unfortunately common occurrence (Rogers \& Faulkner, 1987), and one that is excessively used by black clients (see 


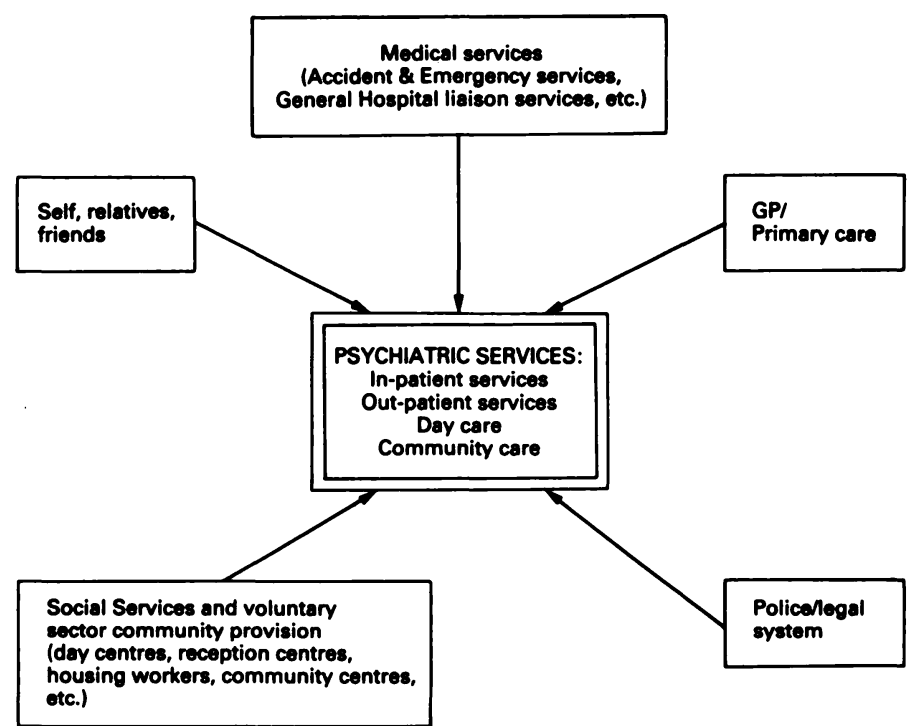

FIG. 1. Access to psychiatric services: a framework.

above). Because of its aversive nature for the clients concerned, it is clearly desirable to minimise this form of access to services. The availability and acceptability of alternative services would appear to be a critical factor.

Continuing psychiatric care may be offered within hospital-based and community psychiatric services themselves, but it may also involve social services, voluntary sector, GP input and family or friends. The relative balance between these will, at a service level, be determined by local availability and co-ordination of services. However, this may be another area where services operate differently for blacks and whites. Perkins \& Rowland (1986) found that $50 \%$ of white patients as compared with only $23 \%$ of black patients referred to a psychiatric rehabilitation and continuing care service were successfully engaged with that service. This may be a reflection of black patients' experience of services prior to their referral for continuing care. Compulsory admission and detention, and police involvement in the initial stages of contact are likely to lead to a negative view of psychiatric care that persists throughout the persons contact, and a higher chance of denial of the need for help.

Thus it is proposed that the relative importance and use of different means of accessing psychiatric care will vary depending upon a series of individual and service parameters. On the individual side, the way in which people perceive or understand the problems they experience, their knowledge and understanding of available services (psychiatric and non-psychiatric) and the perceived 'user-friendliness' of services will all be important. In addition, the range of services available, their geographical location, the psychiatric expertise of non-psychiatric services and the relationship between both psychiatric and nonpsychiatric services and the community at large will be important.

There is no blueprint for the provision of effective psychiatric services: a different balance between agencies might be appropriate in different areas. However, with current efforts to change services it is important that providers investigate the patterns that exist and the impact of changes upon these. With the devolution of services it is not sufficient to look at the operation of articular aspects (e.g. a general practice, a community mental health centre) without consideration of the overall picture.

The evidence of differential service usage by blacks serves as a stimulus for the development of a broader perspective of service usage. The framework presented here is one of relevance to all service users. It offers a structure for investigating local patterns of provision and usage, and offers some relevant variables to consider in changing and developing services.

\section{References}

Francis, E., David, J., Johnson, N. \& Sashidharan, S. P. (1989) Black people and psychiatry in the UK: an alternative to institutional care. Psychiatric Bulletin, 13, 482-485.

GolDberg, D. \& HuXLeY, P. (1980) Mental Illness in the Community. London: Tavistock. 
Harrison, G., Owens, D., Holton, A., Neilson, D. \& Boot, D. (1988) A prospective study of severe mental disorder in Afro-Caribbean patients. Psychological Medicine, 18, 643-657.

Ineichen, B., Harrison, G. \& Morgan, H. G. (1984) Psychiatric hospital admissions in Bristol. I. Geographic and ethnic factors. British Journal of Psychiatry, 145, 600-604.
PERKINS, R. E. \& Rowlands, L. (1986) Planning community services for people with major long-term needs: The Maudsley experience. Paper presented at National MIND/Maudsley Joint Conference, Institute of Psychiatry, London.

Rogers, A. \& Faulkner, A. (1987) A Place of Safety: MIND's Research into Police Referrals to the Psychiatric Services, London: MIND Publications.

\title{
The white coat and the liaison psychiatrist
}

\author{
Alan N. Wear, Squibb Research Fellow, Oxford Project to Investigate Memory and \\ Ageing, Radcliffe Infirmary, Oxford OX2 6HE
}

Medical care in general hospitals is a collective activity and liaison psychiatrists may become part of this process. Cornerstones of successful management are co-operation with colleagues and 'teamwork', although these elusive goals are not always achieved. A shared uniform is one possible solution to improve this teamwork, the white coat being the livery of the hospital doctor. Furthermore, patients may appreciate a uniform. One survey of 200 North American general hospital in-patients showed the white coat to be surprisingly popular (Dunn et al, 1987); $65 \%$ of those replying wanted to see their doctor in a white coat. But the white coat is often unpopular with doctors and perhaps a more relevant question is whether it makes any difference to patient behaviour.

In psychiatric wards this has been studied in relation to nursing uniform. One study (Klein et al, 1972) could detect no difference in patient behaviour under a variety of dress conditions, but another study did find an effect (Rinn, 1976). In a series of six week periods, when the staff wore street clothes, there was a reduction in aggressive behaviour, medication refusals and self-punitive responses as compared to similar periods of study with staff wearing either uniform or a mixture of uniform and street clothes. It was concluded that street clothes create a therapeutic milieu. No parallel studies have been undertaken in general hospitals, so the psychiatrist can choose.
Does he join the company and wear the uniform or are there other ways of working with general hospital patients and colleagues?

To find out what happens in practice, a small survey was undertaken. A short questionnaire was sent to consultants in adult mental illness in the Oxford region and to selected senior registrars working with the Liaison Service in Oxford $(n=66)$. A short letter of explanation was included.

\section{Findings}

Of 66 questionnaires sent, 50 were returned giving a response rate of $75 \%$. The questions and responses are set out below:

Do you ever wear a white coat in the course of your clinical practice?

Eighty-eight per cent of respondents never wore a white coat at any time. The frequency with which this group worked in the general hospital varied from daily to less than one visit per month, with a modal value of weekly. Comparison with the $12 \%$ of respondents who did use a white coat is difficult because of the sevenfold difference in size of the two groups. However, among white coat wearers, the modal frequency for general hospital work was daily with a range from daily to less than once per month. This 